\title{
Variability in blood lipid affects the neutrophil to lymphocyte ratio in patients who have undergone elective percutaneous coronary intervention: $A$ retrospective study
}

\section{Liding Zhao}

Zhejiang University School of Medicine Sir Run Run Shaw Hospital

\section{Tian Xu}

Zhejiang University School of Medicine Sir Run Run Shaw Hospital

Ya Li

Zhejiang University School of Medicine Sir Run Run Shaw Hospital

\section{Yi Luan}

Zhejiang University School of Medicine Sir Run Run Shaw Hospital

Qingbo Lv

Zhejiang University School of Medicine Sir Run Run Shaw Hospital

\section{Guosheng Fu}

Zhejiang University School of Medicine Sir Run Run Shaw Hospital

Wenbin Zhang ( $D$ 3313011@zju.edu.cn )

Zhejiang University School of Medicine Sir Run Run Shaw Hospital

\section{Research}

Keywords: Variability, blood lipid, neutrophil to lymphocyte ratio, percutaneous coronary intervention

Posted Date: February 20th, 2020

DOl: https://doi.org/10.21203/rs.2.24079/v1

License: (c) (i) This work is licensed under a Creative Commons Attribution 4.0 International License. Read Full License

Version of Record: A version of this preprint was published at Lipids in Health and Disease on June 3rd, 2020. See the published version at https://doi.org/10.1186/s12944-020-01304-9. 


\section{Abstract}

\section{Background}

Atherosclerosis is associated with chronic inflammation and lipid metabolism. The neutrophil to lymphocyte ratio (NLR) as an indicator of inflammation has been confirmed to be associated with cardiovascular disease prognosis. However, few studies have explored the effects of blood lipid variability on NLR. We aimed to explore the relationship between variability in blood lipid levels and NLR.

Methods

The association between variability in blood lipids and NLR was assessed with both univariate and multivariate linear regression. Multivariate linear regression was also performed for a subgroup analysis.

Results

The variability of HDL-C ([区] 4.008, SE 0.503, p-value<0.001) and LDL-C ([区] 0.626, SE 0.164, pvalue $<0.001$ ) were risk factors for the NLR value, although baseline LDL-C and HDL-C were not risk factors for NLR values. Variability of HDL-C ([区] 4.328, SE 0.578, p-value<0.001) and LDL-C ([区] 0.660, SE 0.183 , $p$-value $<0.001$ ) were risk factors for NLR variability. Subgroup analysis demonstrated that the relationship between variability of LDL-C and NLR was consistent with the trend of the total sample for those with or without diabetes mellitus, controlled blood lipid, statins, atorvastatin or rosuvastatin. The relationship between the variability of HDL-C and NLR was consistent with the trend of the total sample in all subgroups.

\section{Conclusion}

The variability of HDL-C and LDL-C are risk factors for the value and variability of NLR, while the relationship between variability of HDL-C and NLR is more stable than the variability of LDL-C in the subgroup analysis.

\section{Background}

Atherosclerosis, which is associated with lipid metabolism, is a common disease characterized by lipid deposition of the arterial intimal layer as well as formation of atherosclerotic plaques[1, 2].

Atherosclerosis accounts for elevated morbidity and mortality worldwide[3]. It has recently been found that blood lipid theory is key for the development of atherosclerosis and that low-density lipoprotein cholesterol (LDL-C) plays a key role in this[1]. Indeed, elevated levels of triglyceride (TG) and LDL-C in serum and a decrease in high-density lipoprotein cholesterol (HDL-C) are considered the lipid triads of atherosclerosis[4].

Atherosclerosis is also an inflammatory process that responds to various risk factors[5]. Chronic inflammation of the arterial wall is important for the development of atherosclerosis[6]. As a cost- 
effective, readily available indicator of inflammation, the neutrophil to lymphocyte ratio (NLR) has been shown to be associated with the severity and prognosis of many cardiovascular diseases, including coronary atherosclerosis[7, 8]. Even in the typical white blood cell count range, a higher NLR is associated with atherosclerotic events[9]. In both healthy people[10] and coronary artery disease (CAD) patients[11], low HDL-C has been shown to correlate with the rise of NLR, although whether the variability of lipid protein has any effect on NLR remains unclear.

We set out to investigate the relationship of blood lipids as well as their variability with NLR in patients who were undergoing elective percutaneous coronary intervention ( $\mathrm{PCl})$.

\section{Methods}

\section{Population and procedures}

This single center, observational, retrospective study analyzed data from 4445 patients consecutively admitted to the Sir Run Run Shaw Hospital, Zhejiang University in China between January 2009 and April 2019. Inclusion criteria were as follows: (1) patients must have undergone elective percutaneous coronary intervention; (2) NLR and lipid values during follow-up such as total cholesterol (TC), TG, LDL-C, HDL-C were available; (3) patients were followed up three times or more in the outpatient clinic within one year following PCl.

Participants were excluded if their C-reactive protein (CRP) $\nabla 10 \mathrm{mg} / \mathrm{L}$, their white blood cell count $(W B C) \triangle 10 * 10^{\wedge} 9 / L$, they had congenital heart disease, valvular heart disease, heart failure, peripheral arterial disease, severe renal or hepatic dysfunction, hematological disorders, history of malignancy, acute or chronic infection.

All PCl procedures were carried out by experienced interventional cardiologists using the femoral or radial artery approach, as recommended by current guidelines[12]. Blood samples for baseline information were collected 24 hours before $\mathrm{PCl}$. Three or more follow-ups were carried out in one year for patients undergoing $\mathrm{PCl}$. After an overnight fast, blood samples were taken by antecubital vein puncture to measure routinely evaluated laboratory values. Total leucocyte count and its subtypes, including neutrophil and lymphocyte, as well as monocyte and platelet count were analyzed using an automated blood cell counter. Lipid values such as total cholesterol (TC), triglycerides (TG), low-density lipoprotein cholesterol (LDL-C), high-density lipoprotein cholesterol (HDL-C), and very low-density lipoprotein (VLDL) were also measured. The study was given approval by the Ethics Committee of Sir Run Run Shaw Hospital of Zhejiang University.

\section{Definitions}

HDL-C(STDEV), LDL-C(STDEV), TG(STDEV) and TC(STDEV) refer to the variability of HDL-C, LDL-C, TG and TC, respectively. These were expressed as standard deviations, calculated from follow-up results. The 
value of NLR was the mean of the follow-up results. Patients' medical records from when they were hospitalized were used as baseline indicators. Smoking was defined as currently smoking or stopping less than one month ago. Heart failure was defined by EF $<40 \%$ or NT-pro BNP $>2000 \mathrm{pg} / \mathrm{ml}$.

\section{Statistical analysis}

Statistical analysis was performed using SPSS software version 22.0 (SPSS Inc., Chicago, IL, USA). Continuous variables were non-normally distributed and presented as medians (25-75\%). Categorical variables were represented as $\mathrm{n}(\%)$. Univariate analysis and multivariate regression analysis for each factor were performed by linear regression analysis. All reported $p$-values were two-sided, and $p$-values of $<0.05$ were considered statistically significant.

\section{Results}

\section{Baseline characteristics}

In present study, 4445 patients who had undergone elective PCl at the Sir Run Run Shaw Hospital between January 2009 and April 2019 were included, according to the inclusion and exclusion criteria. Participants' median age was 64 (52-71), 71.9\% were men, $63.4 \%$ had hypertension and $25.6 \%$ had diabetes mellitus. Demographic information, laboratory examination and baseline medication can be seen in Table 1. 
Table 1

Baseline characteristics of the sample.

\begin{tabular}{|c|c|}
\hline & Total samples $(n=4445)$ \\
\hline Age(Years) & $64.00(58.00-71.00)$ \\
\hline Man, N(\%) & 3198(71.9\%) \\
\hline BMI & $24.73(22.64-26.10)$ \\
\hline Current smoking, N(\%) & $1131(25.4 \%)$ \\
\hline Diabetes, N(\%) & $1139(25.6 \%)$ \\
\hline Hypertension, N(\%) & $2817(63.4 \%)$ \\
\hline Previous MI, N(\%) & $97(2.2 \%)$ \\
\hline Previous PCI, N(\%) & $217(4.9 \%)$ \\
\hline Stable angina pectoris & $953(21.4 \%)$ \\
\hline \multicolumn{2}{|l|}{ Laboratory examination } \\
\hline NLR & $2.64(1.94-3.95)$ \\
\hline WBC $\left(\times 10^{\wedge} 9 / L\right)$ & $6.60(5.40-8.30)$ \\
\hline $\operatorname{PLT}\left(\times 10^{\wedge} 9 / \mathrm{L}\right)$ & $182.00(149.00-219.63)$ \\
\hline CRP(mg/L) & $1.70(0.70-5.00)$ \\
\hline LDL-C (mmol/L) & $2.22(1.68-2.93)$ \\
\hline $\mathrm{HDL}-\mathrm{C}(\mathrm{mmol} / \mathrm{L})$ & $1.00(0.84-1.20)$ \\
\hline Lipoprotein(mmol/L) & 15.2(7.78-33.20) \\
\hline Total cholesterol(mmol/L) & $4.19(3.47-5.01)$ \\
\hline Triglyceride(mmol/L) & $1.43(1.03-2.04)$ \\
\hline VLDL-C(mmol/L) & $0.62(0.38-0.93)$ \\
\hline Creatinine $(\mu \mathrm{mol} / \mathrm{L})$ & $75.00(64.00-88.40)$ \\
\hline Uric $\operatorname{acid}(\mu \mathrm{mol} / \mathrm{L})$ & $356.00(296.00-424.00)$ \\
\hline LDL-C (STDEV) & $0.46(0.26-0.74)$ \\
\hline
\end{tabular}

Values are expressed as median $(25-75 \%)$ or $n(\%)$ unless otherwise indicated. STDEV indicates the standard deviation calculated from the follow-up results, mean is the average of the results from the follow-up, NLR neutrophil to lymphocyte ratio, WBC white blood cell, PLT platelet, CRP C-creative protein, BMI Body Mass Index, LDL-C low-density lipoprotein cholesterol, HDL-C high-density lipoprotein cholesterol, VLDL-C very low-density lipoprotein cholesterol, ACEI Angiotensin-Converting Enzyme Inhibitors, ARB angiotensin receptor blocker, CCB calcium channel blocker. 


\section{Total samples $(n=4445)$}

\begin{tabular}{ll} 
HDL-C ( STDEV ) & $0.13(0.08-0.19)$ \\
\hline Total cholesterol ( STDEV ) & $0.58(0.35-0.92)$ \\
Triglyceride ( STDEV ) & $0.33(0.19-0.56)$ \\
NLR(mean) & $2.97(2.27-4.11)$ \\
CRP(mean, mg/L) & $1.53(0.80-2.87)$
\end{tabular}

Baseline medication

ACEI, N(\%)

$1136(25.6 \%)$

ARB, N(\%)

$1558(35.1 \%)$

Beta blocker, N(\%)

$2600(58.5 \%)$

CCB, $N(\%)$

1319(29.7\%)

Aspirin, $\mathrm{N}(\%)$

4284(96.4\%)

Clopidogrel , N(\%)

3602(81.0\%)

Ticagrelor, $\mathrm{N}(\%)$

$749(16.9 \%)$

Ezetimibe, N(\%)

853(19.2\%)

Statin, $N(\%)$

4377(98.5\%)

Atorvastatin, $\mathrm{N}(\%)$

2687(60.4\%)

Rosuvastatin, $\mathrm{N}(\%)$

$1559(35.1 \%)$

Pravastatin, $\mathrm{N}(\%)$

23(0.5\%)

Simvastatin, $\mathrm{N}(\%)$

$58(1.3 \%)$

Intensive statin treatment, $\mathrm{N}(\%)$

564(12.7\%)

Values are expressed as median $(25-75 \%)$ or $n(\%)$ unless otherwise indicated. STDEV indicates the standard deviation calculated from the follow-up results, mean is the average of the results from the follow-up, NLR neutrophil to lymphocyte ratio, WBC white blood cell, PLT platelet, CRP C-creative protein, BMI Body Mass Index, LDL-C low-density lipoprotein cholesterol, HDL-C high-density lipoprotein cholesterol, VLDL-C very low-density lipoprotein cholesterol, ACEI Angiotensin-Converting Enzyme Inhibitors, ARB angiotensin receptor blocker, CCB calcium channel blocker.

\section{Results of univariate and multivariate linear regression for the mean of NLR}


The univariate analysis suggested that age, gender, diabetes, hypertension, types of statins, HDL$C(S T D E V), C R P(M E A N)$, creatinine and uric acid were all risk factors for the mean value of NLR during follow-up. In contrast, ezetimibe, baseline TC and baseline HDL-C were protective factors for the mean value of NLR (see Table 2).

Table 2

Results of univariate and multivariate linear regression for the mean of NLR

\begin{tabular}{|c|c|c|c|c|c|c|}
\hline \multirow[t]{2}{*}{ Variable } & \multicolumn{3}{|c|}{ Univariate regression } & \multicolumn{3}{|c|}{ Multiple Regression } \\
\hline & 凶 & SE & $\mathbf{p}$ & 囚 & SE & p \\
\hline Age & 0.047 & 0.004 & $<0.001$ & 0.035 & 0.004 & $<0.001$ \\
\hline Gender & 0.366 & 0.092 & $<0.001$ & 0.491 & 0.098 & $<0.001$ \\
\hline Current smoking & -0.029 & 0.048 & 0.547 & & & \\
\hline Diabetes & 0.278 & 0.094 & 0.003 & 0.054 & 0.094 & 0.570 \\
\hline Hypertension & 0.286 & 0.086 & 0.001 & 0.109 & 0.087 & 0.212 \\
\hline Types of statins & 0.317 & 0.051 & $<0.001$ & 0.350 & 0.053 & $<0.001$ \\
\hline Intensive statin treatment & -0.146 & 0.122 & 0.232 & & & \\
\hline Ezetimibe & -0.252 & 0.106 & 0.017 & -0.032 & 0.109 & 0.772 \\
\hline Baseline TC & -0.109 & 0.033 & 0.001 & -0.182 & 0.050 & $<0.001$ \\
\hline Baseline LDL-C & -0.019 & 0.042 & 0.657 & & & \\
\hline Baseline HDL-C & -0.589 & 0.144 & $<0.001$ & -0.266 & 0.162 & 0.101 \\
\hline LDL-C (STDEV) & 0.070 & 0.112 & 0.531 & 0.626 & 0.164 & $<0.001$ \\
\hline HDL-C ( STDEV ) & 4.648 & 0.048 & $<0.001$ & 4.008 & 0.503 & $<0.001$ \\
\hline TC(STDEV) & 0.069 & 0.089 & 0.438 & & & \\
\hline TG( STDEV ) & -0.079 & 0.058 & 0.170 & & & \\
\hline CRP(MEAN) & 0.400 & 0.025 & $<0.001$ & 0.326 & 0.026 & $<0.001$ \\
\hline Creatinine & 0.006 & 0.001 & $<0.001$ & 0.004 & 0.001 & $<0.001$ \\
\hline Uric acid & 0.001 & $<0.001$ & 0.006 & -0.001 & $<0.001$ & 0.087 \\
\hline
\end{tabular}

Once the univariate analysis was corrected to allow for confounding factors, results from the multivariable logistic regression analysis showed that age, gender, types of statins, HDL-C(STDEV), LDL- 
C(STDEV), CRP(MEAN) and creatinine were all risk factors for the mean value of NLR. Baseline TC was a protective factor for the mean value of NLR (see Table 2).

For HDL-C(STDEV), multivariate linear regression analysis results for each subgroup are stable, showing that HDL-C(STDEV) is a risk factor for the mean value of NLR during the follow-up (see Fig. 1).

In contrast, the relationship between LDL-C(STDEV) and the mean value of NLR was consistent across patients with blood lipid controlled ([区] 0.643, [95\% Cl] 0.249-1.037, p-value $=0.001$ ), diabetes ([区] 1.065, [95\% Cl] 0.442-1.689, p-value $=0.001)$, no diabetes $([\mathbb{\nabla}] 0.459,[95 \% \mathrm{Cl}] 0.083-0.836, \mathrm{p}$-value $=0.017)$, those who were taking statins ([区] 0.778, [95\% Cl] 0.430-1.127, p-value $<0.001)$, taking atorvastatin ([区] $0.654,[95 \% \mathrm{Cl}] 0.255-1.054, \mathrm{p}$-value $=0.001)$ and taking rosuvastatin $([\mathbb{\square}] 0.504,[95 \% \mathrm{Cl}] 0.074-0.934, \mathrm{p}-$ value $=0.022$ ) (see Fig. 2).

\section{Results of univariate and multivariate linear regression for the variability in NLR}

The univariate analysis suggested that age, gender, types of statins, HDL-C(STDEV), CRP(MEAN) and creatinine were all risk factors for NLR variability during follow-up. In contrast, baseline TC and baseline HDL-C were protective factors for NLR variability (see Table 3 ). 
Table 3

Results of univariate and multivariate linear regression for variability in NLR

\begin{tabular}{|c|c|c|c|c|c|c|}
\hline \multirow[t]{2}{*}{ Variable } & \multicolumn{3}{|c|}{ Univariate regression } & \multicolumn{3}{|c|}{ Multiple Regression } \\
\hline & 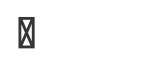 & SE & p & 凶 & SE & p \\
\hline Age & 0.034 & 0.004 & $<0.001$ & 0.024 & 0.005 & $<0.001$ \\
\hline Gender & 0.303 & 0.102 & 0.003 & 0.320 & 0.108 & 0.003 \\
\hline Current smoking & -0.057 & 0.054 & 0.289 & & & \\
\hline Diabetes & 0.125 & 0.105 & 0.232 & & & \\
\hline Hypertension & 0.099 & 0.095 & 0.298 & & & \\
\hline Types of statins & 0.261 & 0.056 & $<0.001$ & 0.304 & 0.061 & $<0.001$ \\
\hline Intensive statin treatment & -0.143 & 0.136 & 0.293 & & & \\
\hline Ezetimibe & -0.214 & 0.117 & 0.068 & & & \\
\hline Baseline TC & -0.079 & 0.036 & 0.029 & -0.175 & 0.055 & 0.002 \\
\hline Baseline LDL-C & 0.008 & 0.047 & 0.859 & & & \\
\hline Baseline HDL-C & -0.553 & 0.160 & 0.001 & -0.381 & 0.185 & 0.040 \\
\hline LDL-C (STDEV) & 0.194 & 0.124 & 0.120 & 0.660 & 0.183 & $<0.001$ \\
\hline HDL-C ( STDEV ) & 4.680 & 0.533 & $<0.001$ & 4.328 & 0.578 & $<0.001$ \\
\hline TC( STDEV ) & 0.168 & 0.099 & 0.089 & & & \\
\hline TG( STDEV ) & 0.003 & 0.064 & 0.964 & & & \\
\hline CRP(MEAN) & 0.321 & 0.029 & $<0.001$ & 0.256 & 0.030 & $<0.001$ \\
\hline Creatinine & 0.005 & 0.001 & $<0.001$ & 0.003 & 0.001 & $<0.001$ \\
\hline Uric acid & 0.001 & $<0.001$ & 0.093 & & & \\
\hline
\end{tabular}

After correction for the confounding factors screened from the univariate analysis, the multivariable linear regression analysis revealed that age, gender, types of statins, HDL-C(STDEV), LDL-C(STDEV), $\mathrm{CRP}(\mathrm{MEAN})$ and creatinine were risk factors for NLR variability. Baseline TC and baseline HDL-C were protective factors for the variability in NLR (see Table 3).

For HDL-C(STDEV), multivariate linear regression analysis results for each subgroup are stable, suggesting that HDL-C(STDEV) is a risk factor for NLR variability during the follow-up (see Fig. 3). 
On the other hand, the relationship between LDL-C(STDEV) and NLR variability was consistent across the patients with controlled blood lipid ([区] 0.699, [95\% Cl] 0.252-1.145, $p$-value $=0.002$ ), diabetes ([区] 0.839, $[95 \% \mathrm{Cl}] 0.151-1.528, \mathrm{p}$-value $=0.017)$, those with no diabetes $([\mathbb{\nabla}] 0.602,[95 \% \mathrm{Cl}] 0.181-1.024, \mathrm{p}$-value $=$ $0.005)$, those taking statins ([区] 0.929, [95\% Cl] 0.524-1.315, p-value < 0.001$)$, atorvastatin ([区] 0.777, [95\% $\mathrm{Cl}] 0.318-1.236$, p-value $=0.001)$ or rosuvastatin $([\mathbb{[}] 0.553,[95 \% \mathrm{Cl}] 0.003-1.072, \mathrm{p}$-value $=0.037)($ see Fig. 4).

\section{Discussion}

The main findings of the current study are as follows: (1) variability of HDL-C and LDL-C were risk factors for the value and variability in NLR; (2) the relationship between variability of HDL-C and NLR was consistent for each subgroup analysis (those with or without diabetes mellitus, controlled or uncontrolled blood lipid, taking statin with ezetimibe or not, and taking rosuvastatin or atorvastatin). The relationship between variability of LDL-C and NLR was also confirmed in most subgroup analyses, except for patients with uncontrolled blood lipid and those taking statins with ezetimibe. Subgroup analysis results suggest that the linear relationship between HDL-C and NLR is more stable than for LDL-C.

Blood lipid levels play a crucial role in the process of atherosclerosis[1, 13]. HDL-C is an independent predictor of coronary heart disease risk[14]. Authors of four large studies have concluded that each increase of $1 \mathrm{mg}$ per deciliter ( $0.03 \mathrm{mmol}$ per liter) in HDL-C is associated with a decrease of 2 to $3 \%$ in future coronary heart disease risk[15]. Low-density lipoprotein has important physiological effects as a carrier for transporting cholesterol to peripheral tissues, although its elevated level is associated with an increased risk of cardiovascular disease[ $[1,16,17]$. NLR can be easily calculated from differential WBC counts, which are widely available and routinely performed. These counts provide additional risk stratification beyond conventional risk scores such as predicting mortality in cardiovascular diseases[18]. A high NLR is a predictor of atherosclerosis progression $[8,19,20]$. As a protective factor for blood vessels, HDL-C has been observed in both healthy people[10] and CAD patients[11] as associated with NLR levels at lower levels. Increased NLR values may indicate subclinical inflammation[21]. However, few authors have focused on the relationship between variability in blood lipids and NLR.

Visit-to-visit LDL-C variability was found to be an independent predictor of cardiovascular events for patients with stable coronary artery disease in the TNT trial[22], while Boey et al. confirmed that visit-tovisit LDL-C and HDL-C variability are associated with occurrence of a MACE at five year follow-up following STEMI[23]. Results of the current study further support the clinical relevance of LDL-C and HDL$C$ variability by showing that LDL-C and HDL-C variability are risk factors for NLR. In contrast to Boey et al., the focus of this study is on NLR rather than clinical outcomes. The current study sample was Asian rather than Caucasian patients who were followed-up for one year following PCl. In addition, by confirming the variability in HDL-C and LDL-C can affect NLR variability, we further explored the clinical connection between blood lipid and NLR. The results of the current study may have certain reference significance for lipid-lowering therapy in patients at this time. 
The exact mechanism for increased variability in LDL-C, HDL-C and an increased risk of NLR remains unknown. However, several hypotheses have been suggested. Statins primarily (although not exclusively) stabilize plaque[24] through a cholesterol-dependent mechanism, thereby reducing plaque cholesterol levels[25]. In turn, lipid reduction inhibits inflammation as well as reducing collagen hydrolyzing activity and thrombotic potential. LDL-C variability may result in instability of the vessel wall due to damage to cholesterol-dependent plaque stabilization mechanisms[22], thus increasing the likelihood of plaque vulnerability and rupture, although most ruptures do not cause clinic events. Conversely, high HDL-C variability may lead to plaque instability by impairing cholesterol outflows in surrounding tissues and macrophages, thus increasing the risk of damage to the vessel wall and inducing inflammation[26]. Additionally, LDL particles in circulation can penetrate the endothelium of the arterial wall and be oxidized, promoting inflammation and causing endothelial damage[27]. Neutrophils indicate systemic inflammatory states, while lymphocytes suggest fibrotic hyperplasia and homeostasis of overall inflammation. Both of these respond to inflammation caused by arterial plaque[2, 28, 29]. Further to this, vasculogenesis, a process involved in cardiovascular injury, initiates various chronic adaptive processes including elevation of circulating neutrophils, which will further damage vascular endothelial cells through processes such as inflammatory reactions and oxidative stress[30], partially explaining this study's results. Interestingly, the use of subgroup analysis in this study showed that the relationship between the variability of HDL-C and NLR is more stable than the variability of LDL-C, which deserves further investigation. In clinical practice, there is no effective treatment method for controlling NLR. We found that blood lipid variability is an independent risk factor for NLR, suggesting that the control of blood lipid variability can affect NLR, thereby improving the prognosis of patients undergoing PCI.

Our study has several limitations. First, as a single center, retrospective observational study, residual confounding or selection bias cannot be excluded, which is inherent to any retrospective study. Second, we did not take patients' statin dose as a factor of inquiry, which may affect blood lipid variability. Third, we did not rule out factors that may affect NLR, such as hypertension and diabetes, but instead used them as corrective factors in the multivariate regression. Last but not least, we failed to collect information on patients' interleukin-6, which can reflect the inflammatory status in vivo. Additionally, we did not focus on the relationship of CRP, another indicator of inflammation, with blood lipid variability, but included it in multivariate regression.

\section{Conclusion}

The variability of HDL-C and LDL-C are risk factors for NLR, while the relationship between the variability of HDL-C and NLR is more stable than the variability of LDL-C.

\section{Abbreviations}

NLR: neutrophil to lymphocyte ratio; LDL-C: low-density lipoprotein cholesterol; HDL-C: high-density lipoprotein cholesterol; TG: triglyceride; TC: total cholesterol; CAD: coronary artery disease; PCI: 
percutaneous coronary intervention; CRP: C-reactive protein; WBC: white blood cell count; VLDL: very lowdensity lipoprotein; $\mathrm{Cl}$ : confidence intervals.

\section{Declarations}

\section{Ethics approval and consent to participate}

The study was given approval by the Ethics Committee of Sir Run Run Shaw Hospital of Zhejiang University.

\section{Consent for publication}

Not applicable.

\section{Availability of data and materials}

The datasets used and/or analyzed during the current study are available from the corresponding author on reasonable request.

\section{Competing interests}

The authors declare that they have no competing interests.

\section{Funding}

This work was supported by the Zhejiang Natural Science Fund (LY18H020007), National Natural Science Foundation of China (81700213).

\section{Authors' contributions}

WBZ conceived and designed the study. LDZ, TX, Ya Li and Yi Luan performed the study. LDZ, TX, QBL and GSF analyzed the data. LDZ, TX and Ya Li wrote the paper. All authors reviewed drafts and approved the final version of the manuscript.

\section{Acknowledgements}

We are grateful for the language polish service provided by EditSprings.

\section{References}

1. Glass CK, Witztum JL: Atherosclerosis. the road ahead. Cell 2001, 104:503-516.

2. Rezende AB, Neto NN, Fernandes LR, Ribeiro AC, Alvarez-Leite JI, Teixeira HC: Splenectomy increases atherosclerotic lesions in apolipoprotein E deficient mice. J Surg Res 2011, 171:e231-236. 
3. Afari ME, Bhat T: Neutrophil to lymphocyte ratio (NLR) and cardiovascular diseases: an update. Expert Rev Cardiovasc Ther 2016, 14:573-577.

4. Petroianu A, Veloso DF, Alberti LR, de Souza Vasconcellos L: Plasma lipid alterations after total splenectomy, subtotal splenectomy and splenic auto-implants in rats. J Gastroenterol Hepato/ 2008, 23:e221-224.

5. Libby P, Theroux P: Pathophysiology of coronary artery disease. Circulation 2005, 111:3481-3488.

6. Balta S, Celik T, Mikhailidis DP, Ozturk C, Demirkol S, Aparci M, lyisoy A: The Relation Between Atherosclerosis and the Neutrophil-Lymphocyte Ratio. Clin Appl Thromb Hemost 2016, 22:405-411.

7. Kaya MG, Akpek M, Lam YY, Yarlioglues M, Celik T, Gunebakmaz O, Duran M, Ulucan S, Keser A, Oguzhan A, Gibson MC: Prognostic value of neutrophil/lymphocyte ratio in patients with ST-elevated myocardial infarction undergoing primary coronary intervention: a prospective, multicenter study. Int J Cardio/ 2013, 168:1154-1159.

8. Kalay N, Dogdu O, Koc F, Yarlioglues M, Ardic I, Akpek M, Cicek D, Oguzhan A, Ergin A, Kaya MG: Hematologic parameters and angiographic progression of coronary atherosclerosis. Angiology 2012, 63:213-217.

9. Horne BD, Anderson JL, John JM, Weaver A, Bair TL, Jensen KR, Renlund DG, Muhlestein JB, Intermountain Heart Collaborative Study G: Which white blood cell subtypes predict increased cardiovascular risk? J Am Coll Cardio/ 2005, 45:1638-1643.

10. Tok D, Iscen S, Ozenc $S$ : Neutrophil-lymphocyte ratio is associated with low high-density lipoprotein cholesterol in healthy young men. SAGE Open Med 2014, 2:2050312114532079.

11. Prajapati JH, Sahoo S, Nikam T, Shah KH, Maheriya B, Parmar M: Association of high density lipoprotein with platelet to lymphocyte and neutrophil to lymphocyte ratios in coronary artery disease patients. J Lipids 2014, 2014:686791.

12. Levine GN, Bates ER, Blankenship JC, Bailey SR, Bittl JA, Cercek B, Chambers CE, Ellis SG, Guyton RA, Hollenberg SM, et al: 2011 ACCF/AHA/SCAI Guideline for Percutaneous Coronary Intervention: executive summary: a report of the American College of Cardiology Foundation/American Heart Association Task Force on Practice Guidelines and the Society for Cardiovascular Angiography and Interventions. Circulation 2011, 124:2574-2609.

13. Carr SS, Hooper AJ, Sullivan DR, Burnett JR: Non-HDL-cholesterol and apolipoprotein B compared with LDL-cholesterol in atherosclerotic cardiovascular disease risk assessment. Pathology 2019, 51:148-154.

14. Barter P, Gotto AM, LaRosa JC, Maroni J, Szarek M, Grundy SM, Kastelein JJ, Bittner V, Fruchart JC, Treating to New Targets I: HDL cholesterol, very low levels of LDL cholesterol, and cardiovascular events. N Engl J Med 2007, 357:1301-1310.

15. Gordon DJ, Probstfield JL, Garrison RJ, Neaton JD, Castelli WP, Knoke JD, Jacobs DR, Jr., Bangdiwala S, Tyroler HA: High-density lipoprotein cholesterol and cardiovascular disease. Four prospective American studies. Circulation 1989, 79:8-15. 
16. Qamar A, Libby P: Low-Density Lipoprotein Cholesterol After an Acute Coronary Syndrome: How Low to Go? Curr Cardiol Rep 2019, 21:77.

17. Katzmann JL, Laufs U: New Insights in the Control of Low-Density Lipoprotein Cholesterol to Prevent Cardiovascular Disease. Curr Cardiol Rep 2019, 21:69.

18. Balta S, Celik T, Mikhailidis DP, Ozturk C, Demirkol S, Aparci M, lyisoy A: The Relation Between Atherosclerosis and the Neutrophil-Lymphocyte Ratio. Clin Appl Thromb Hemost 2016, 22:405-411.

19. Nam KW, Kwon HM, Jeong HY, Park JH, Kim SH, Jeong SM: High neutrophil to lymphocyte ratios predict intracranial atherosclerosis in a healthy population. Atherosclerosis 2018, 269:117-121.

20. Corriere T, Di Marca S, Cataudella E, Pulvirenti A, Alaimo S, Stancanelli B, Malatino L: Neutrophil-toLymphocyte Ratio is a strong predictor of atherosclerotic carotid plaques in older adults. Nutr Metab Cardiovasc Dis 2018, 28:23-27.

21. Balta S, Demirkol S, Unlu M, Arslan Z, Celik T: Neutrophil to lymphocyte ratio may be predict of mortality in all conditions. Br J Cancer 2013, 109:3125-3126.

22. Bangalore S, Breazna A, DeMicco DA, Wun CC, Messerli FH, Committee TNTS, Investigators: Visit-tovisit low-density lipoprotein cholesterol variability and risk of cardiovascular outcomes: insights from the TNT trial. J Am Coll Cardiol 2015, 65:1539-1548.

23. Boey E, Gay GM, Poh KK, Yeo TC, Tan HC, Lee CH: Visit-to-visit variability in LDL- and HDL-cholesterol is associated with adverse events after ST-segment elevation myocardial infarction: A 5-year followup study. Atherosclerosis 2016, 244:86-92.

24. Thondapu V, Kurihara O, Yonetsu T, Russo M, Kim HO, Lee H, Soeda T, Minami Y, Jang IK: Comparison of Rosuvastatin Versus Atorvastatin for Coronary Plaque Stabilization. Am J Cardio/ 2019, 123:15651571.

25. Crisby M, Nordin-Fredriksson G, Shah PK, Yano J, Zhu J, Nilsson J: Pravastatin treatment increases collagen content and decreases lipid content, inflammation, metalloproteinases, and cell death in human carotid plaques: implications for plaque stabilization. Circulation 2001, 103:926-933.

26. Navab M, Reddy ST, Van Lenten BJ, Fogelman AM: HDL and cardiovascular disease: atherogenic and atheroprotective mechanisms. Nat Rev Cardio/ 2011, 8:222-232.

27. Sloop GD: Atherosclerosis-an inflammatory disease. N Engl J Med 1999, 340:1928; author reply 1929.

28. Pillay J, Kamp VM, van Hoffen E, Visser T, Tak T, Lammers JW, Ulfman LH, Leenen LP, Pickkers P, Koenderman L: A subset of neutrophils in human systemic inflammation inhibits $\mathrm{T}$ cell responses through Mac-1. J Clin Invest 2012, 122:327-336.

29. Drew AF, Tipping PG: T helper cell infiltration and foam cell proliferation are early events in the development of atherosclerosis in cholesterol-fed rabbits. Arterioscler Thromb Vasc Biol 1995, 15:1563-1568.

30. Siminiak T, Flores NA, Sheridan DJ: Neutrophil interactions with endothelium and platelets: possible role in the development of cardiovascular injury. Eur Heart $J$ 1995, 16:160-170. 


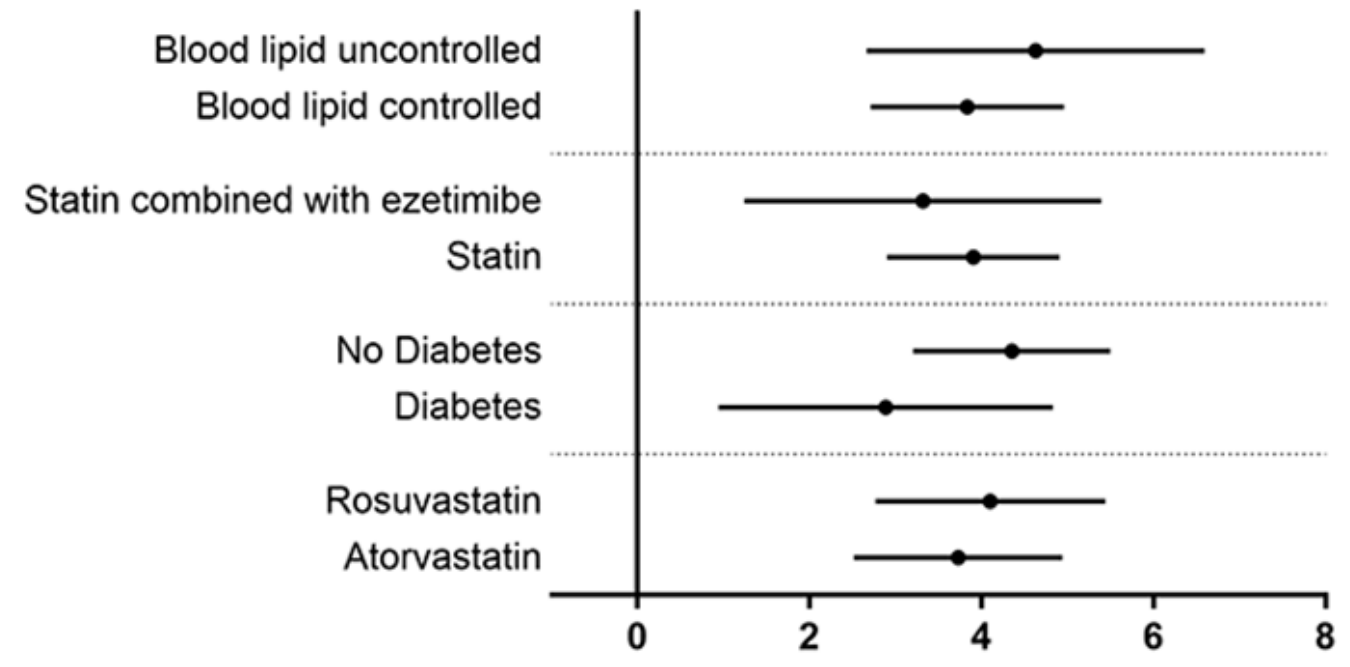

$\begin{array}{cc}\beta(95 \% \mathrm{Cl}) & \text { P value } \\ 4.627(2.660-6.593) & <0.001 \\ 3.832(2.709-4.956) & <0.001 \\ 3.317(1.241-5.393) & 0.002 \\ 3.905(2.902-4.907) & <0.001 \\ 4.351(3.204-5.498) & <0.001 \\ 2.885(0.940-4.830) & 0.004 \\ 4.101(2.765-5.437) & <0.001 \\ 3.727(2.515-4.938) & <0.001 \\ & \end{array}$

Figure 1

Subgroup analysis of NLR and variability of HDL-C. Multivariate linear regression results for the variability of HDL-C and NLR. Cl confidence intervals

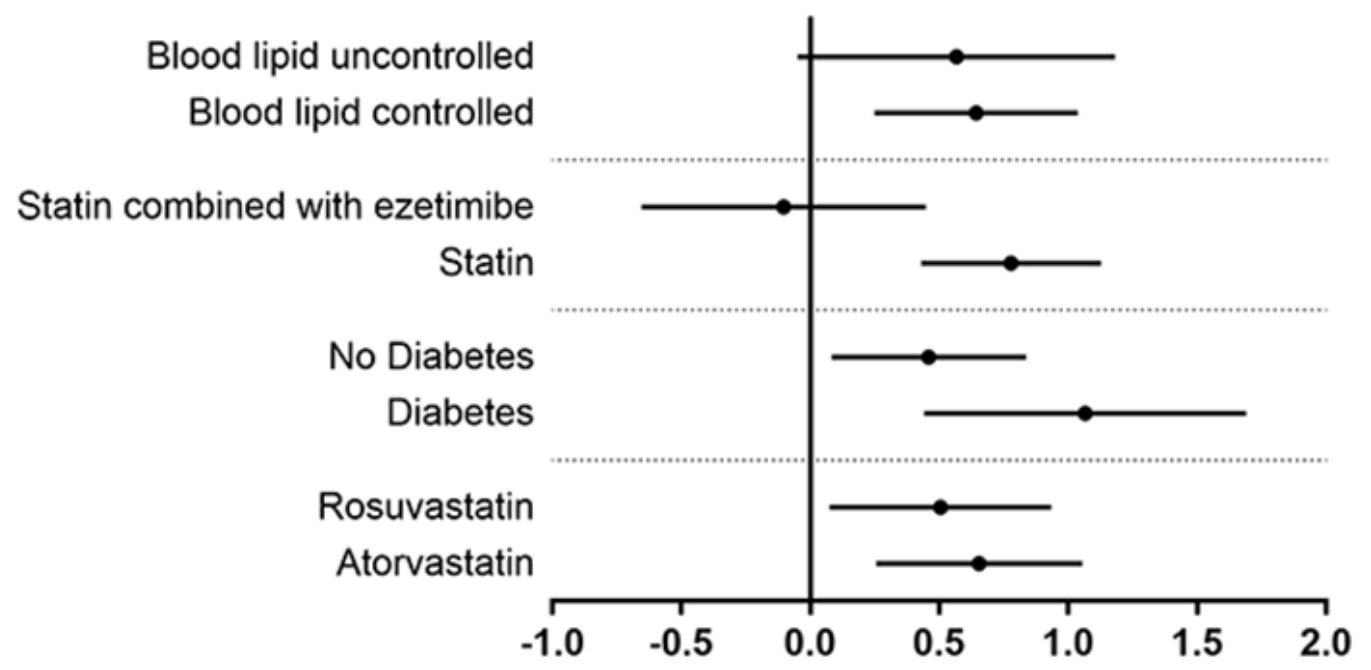

$\beta(95 \% \mathrm{Cl}) \quad$ Pvalue

$0.566(-0.049-1.181) \quad 0.071$

$0.643(0.249-1.037) \quad 0.001$

$-0.103(-0.654-0.448) \quad 0.714$

$0.778(0.430-1.127) \quad<0.001$

$0.459(0.083-0.836) \quad 0.017$

$1.065(0.442-1.689) \quad 0.001$

$0.504(0.074-0.934) \quad 0.022$

$0.654(0.255-1.054) \quad 0.001$

\section{Figure 2}

Subgroup analysis of NLR and variability of LDL-C. Multivariate linear regression results for the variability of LDL-C and NLR. Cl confidence intervals 


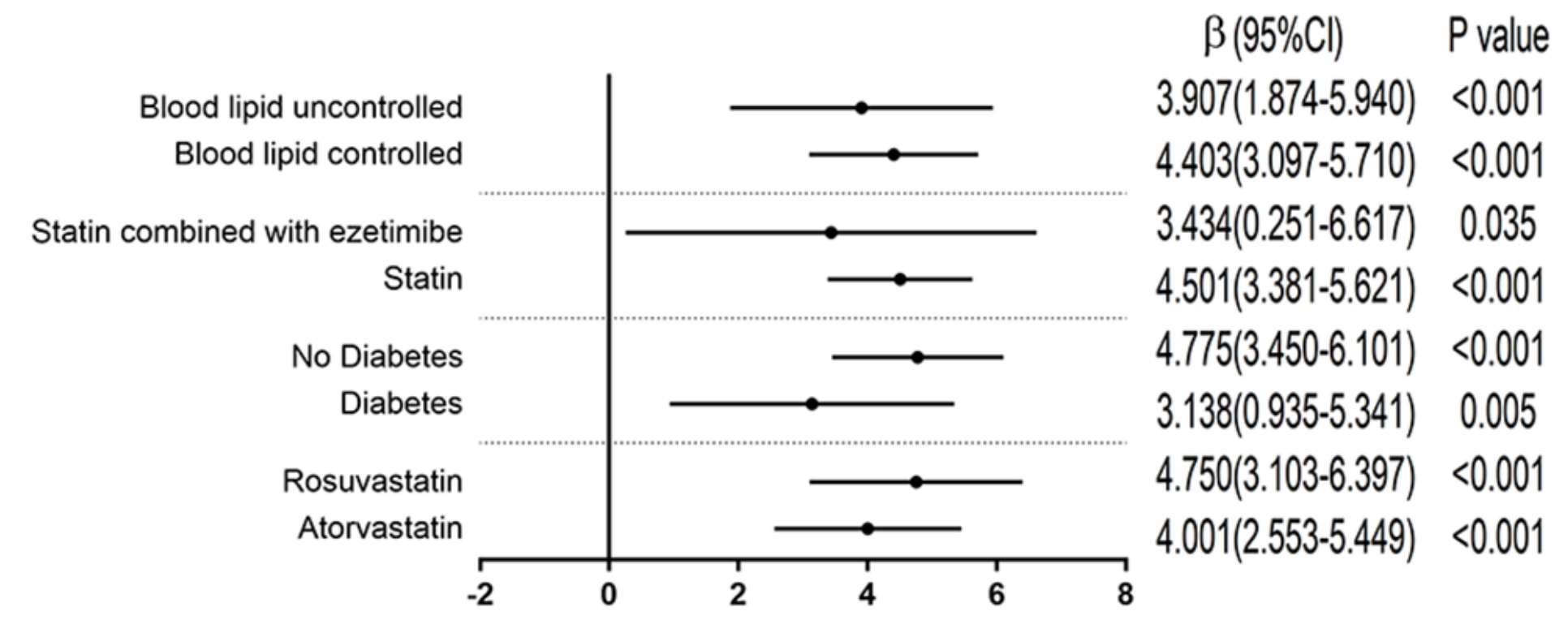

Figure 3

Subgroup analysis of variability in NLR and variability of HDL-C. Multivariate linear regression results for the variability of HDL-C and variability in NLR. CI confidence intervals

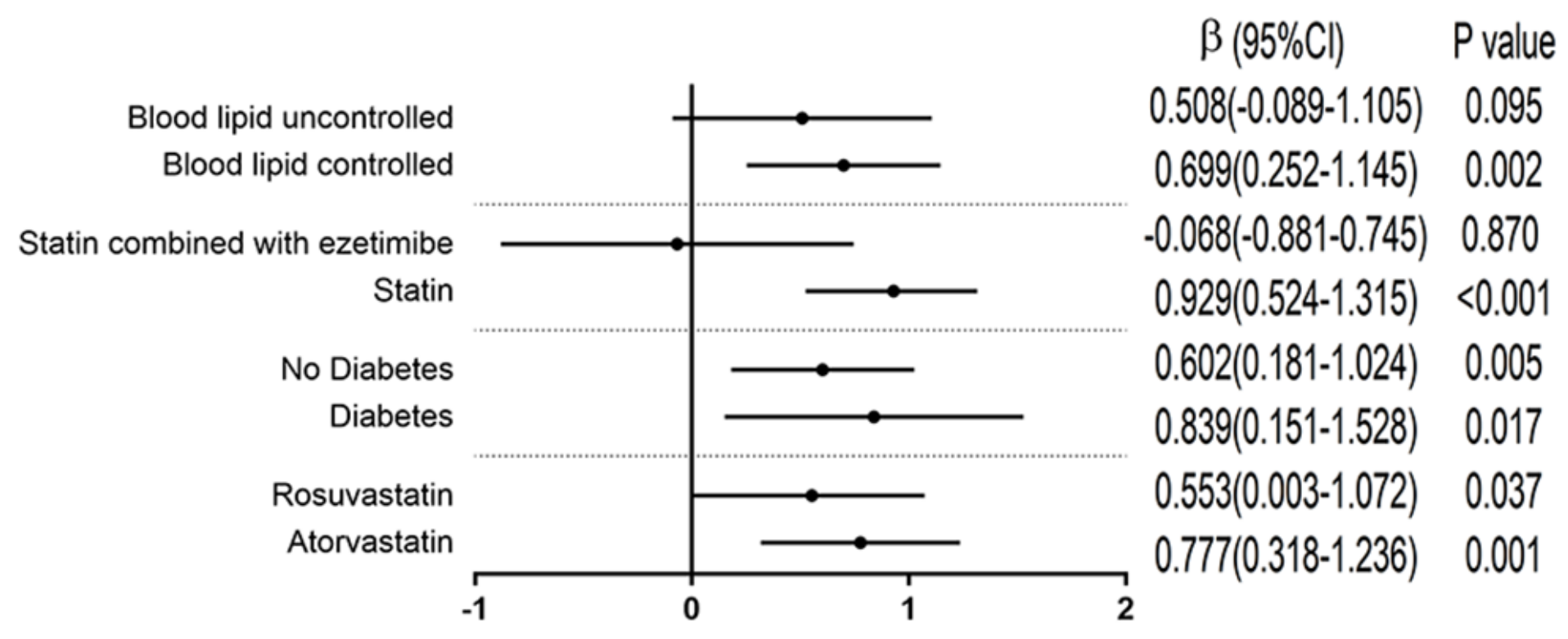

Figure 4

Subgroup analysis of variability in NLR and variability of LDL-C. Multivariate linear regression results for the variability of LDL-C and variability in NLR. Cl confidence intervals 